Title: Gender and the achievement of skilled status in the workplace - the case of women leaders in the UK Fire and Rescue Service.

\title{
Ruth Woodfield
}

School of Management, University of St Andrews

\section{Abstract}

This article focuses on a hitherto un-researched group: women leaders within the UK Fire and Rescue Service. The process of modernising the Fire and Rescue Service has increased expectations of workforce diversification and of women more easily entering, and progressing within, the organisation. Here, however, participants' commentary testified to the difficulties faced when seeking recognition as a skilled woman in this context given the persistence of firefighter men as the occupational ideal type. Achieving recognition for both physical and non-physical skills remained an embodied, gendered and contested process and one that was not eased by promotion. Participants identified the heightened visibility that accompanied leadership as especially problematic. The findings suggest that some new elements of the modernised UK Fire and Rescue Service culture are less successful than they might be at supporting women in leadership roles.

\section{Keywords}

Body, gender, Fire and Rescue Service, leadership, management, skill, work. 


\section{Introduction}

A wealth of evidence supports the basic tenet of feminist scholarship that the overarching meta-theme of gender dictates commonsense conceptualisations of men's labour as positive, productive and skillful, and women's as less valuable, comparatively unskilled, and focused on production's poor relation: reproduction (Mead 1949; Ortner and Whitehead 1981; Phillips and Taylor 1980; Traweek 1989). An underlying principle of this finding is that skill is 'an elusive concept' (Grugulis and Vincent 2009, 598) and that judgments about skilled status are not neutrally made. Rather they are mediated through a matrix of socio-political assumptions about the embodied nature of the worker rather than the work undertaken (Henwood 1987). Workers' bodies are 'status carriers' (Watts, 2009: 516), and skill recognition 'saturated' (Philips and Taylor 1980: 79) with bias towards men and masculine traits. When an occupation is male-dominated, and the occupational profile masculine, women's attempts to be recognised as skilled is a doubly difficult process because they are further challenged by the context-specific, socio-political construct of men as the 'ideal type' of worker and women as the 'wrong' sex' (Hatmaker 2012, 2).

This article provides an empirical exploration of this important social phenomenon within new research terrain: the Fire and Rescue Service (FRS). It contributes to our understanding of how women workers experience the recognition of their physical and non-physical skills within the Service, and the particular challenges they face when promoted to a management position. The FRS provides 'fertile ground' for the study of gendered workplace experiences; it is maledominated, has an archetypal masculine occupational identity, yet there is a 'relative scarcity of sociological research into its occupational locales' (Thurnell-Read and 
Parker 2008, 127). Further, within existing FRS research, men's experience has dominated the agenda.

\section{Gender, Skill and the Fire and Rescue Service}

The UK FRS is a quasi-military organization, originally modeled on the Royal Navy, with uniforms, a clear chain of command, and a system of ranks; since 2004 these are formally referred to as 'roles' in most Services, although informally use of the term 'ranks' remains commonplace. Approximately eighty percent of FRS employees are 'operational' personnel, firefighters, while some 20 percent work in 'non-operational' roles (CLG 2010a). These include generic roles, in IT, HR, and Finance, but also FRS-specific roles, for example: emergency call processing; complex risk assessment roles; fire and flood education roles. Some non-operational staff are co-located with firefighters, but some work in centralised regional headquarters. Contact between operational and non-operational staff is nonetheless frequent. All firefighters wear uniforms on duty, while the majority of nonoperational staff does not wear them; indeed, the terms 'uniformed' and 'operational' are frequently used interchangeably. Over 95 percent of firefighters are men and over 95 percent are white (CLG 2010a; CLG 2010b). Although women represent 15 percent of FRS workers overall, the majority of them work in non-operational areas (CLG 2010, 271-2). Most women, therefore, do not work in the organisation's core occupational role or wear a uniform.

\section{The Traditional Fire and Rescue Service and the dominance of physical skill}

Despite the established presence of non-operational staff, the salient occupational profile that dominated both public perception, and the occupational identification of 
many FRS workers during the $20^{\text {th }}$ Century, was the firefighter. This figure occupied a particular and powerful intersection of class, gender, sexuality and ethnicity, being a white, working-class, masculine man, physically fit and physically-oriented, heterosexual, as well as frequently sexualized, but also willing to face considerable danger to save others, and so altruistic and heroic (Baigent 2001; Woodfield 2007). Baigent's 2001 work provides the most detailed exploration of 'firefighters' masculinity' (21). This term denotes a complex mix of beliefs, characteristics and behaviours that developed in conjunction with the Service's military elements and public service ethos, and which included strong role commitment, firm discipline, close and inclusive team-affiliations, alongside traditional masculine risk-taking and validating behaviour, highly exclusionary impulses and practices, and extreme resistance to change. 'Watches', the small, tightly-knit groups forming the daily working context for firefighters, were identified as crucibles for the production of a masculine culture that played a critical role in both the creation of highly effective firefighting crews, but also the creation of some ineffective working relationships, dysfunctions and inefficiencies.

Baigent argues that firefighters' masculinity was 'constructed on the premise that it was only available to (white) men' (21) who cleaved to an occupational identity organised around heroic, blue-collar skills. As such, it was constructed in opposition to white-collar work, to paperwork, which is positioned as academic and feminizing (101), and to management. As remains the case today, firefighters in the traditional Service could advance through a single-tier entry system, ensuring that all senior firefighters had operational experience, and all had the opportunity to rise through the structure from Firefighter through to Chief Fire Officer. Research has concluded, however, that 'career success' was 'evaluated 
differently' in the traditional Fire Service (Woods 2002, 34), noting a generalised distrust of ambition and management, 'because officers were once working-class firefighters' who were considered to have jettisoned their identity to 'become upwardly mobile' (Baigent 2001, 21).

The traditional FRS therefore fell into that category of work with arguably the most entrenched gender-segregation, wherein the ideal type of worker is culturally reified as masculine and superior 'to women and also to weedy, bookish men' (Ness 2012, 662). Women's difficulties fitting in to this 'closed organisation' (Home Office 1999, 21; see also Bain 2002, 7) were identified as particularly challenging, but so were the struggles of non-standard, more cerebral, ambitious or middle-class men, as well as non-operational and non-uniformed workers; all could face considerable challenges achieving recognition and status in the midst of a prevailing 'us' and 'them' mentality (Home Office 1999, 21; Baigent 2001).

Monaghan's work on 'body capital' develops our understanding of the close association between working-class masculine occupational identity and embodied male skill. Building on Bourdieu (1986) and Wacquant's (1995) work on embodied cultural capital, Monaghan's (2002) study of doorstaff claims workingclass men deploy 'body capital' as an economic asset, to signal both their skill and conformity to the dominant 'gendered, working-class constructions of occupational competency' (337). In so doing, they also validate their 'gendered selfhood' (335). Monaghan suggests that body capital 'comprises two main dimensions: body build (size, weight, height and general appearance of the physique) and techniques of the body' (337), including physical ability, but also a 'willingness to risk one's body in performance' (351). The relative possession of body capital is 'extremely salient in relation to in-group typifications, relations and the forging of masculine identities in 
their risk environment' (337). It enables men to recognize, label and grade others hierarchically against the ideal type of worker and becomes 'the primary vehicle' (340) through which they establish and wield power, not just over women, but also between themselves as they distinguish between 'superordinate' and 'subordinate' masculinities (340). Such occupational identities validate privileged forms of masculinity beyond the workplaces they are directly associated with. Baigent notes that traditional 'firefighters' masculinity' conferred 'petty dividends' for FRS men, but also to men more generally and to commonsense assumptions that there is a 'natural' gendered division of labour based on differences in embodied propensities and skill $(2001,97)$.

Monaghan stresses the performative aspects of both body build and technique capital, but notes that women's ability to possess and display masculine body build capital is relatively limited because 'their real material bodies seldom matched the physical proportions of their male colleagues' (341). Resistance to women firefighters in the traditional FRS was focused on precisely these grounds, as they were counterposed to men as physically weaker, less valuable, but also sexually available; a characterization that fed into an understanding that more women in the organisation would disrupt its culture, safety standards and service quality. The Fire Brigades' Union (FBU), has been described as militant (Baigent 2001, 95) and intransigent (Home Office 1999, 49) in terms of its effective and long-standing opposition to management and government interference in the culture and practices of firefighters, and this included its support for rearguard responses to policies designed to increase women firefighter numbers.

When faced with this body-capital deficit, Monaghan suggests, women, and men without 'exemplary masculine bodies' (337), seek instead to capitalize upon 
'their diligently acquired bodily techniques' (342) in the workplace. There is evidence, however, that technically competent women will, in male-dominated and masculine occupational arenas, always remain primarily recognised as marginal to the core worker profile by dint of their manifestly different physical embodiment. Lewis and Simpson $(2010,5)$ suggest that dominant workplace groups establish the 'norm', and the illusion of 'disembodied normativity', possessing 'naturalised', effortless skill. Men in occupations focused around physicality and masculine body capital paradoxically become less physically visible than women, whereas women, and their gender, become more salient. As Kanter (1977) demonstrated, such visibility renders women more likely to face social-political judgments of their skill and value in organisations, and, as they become more manifestly a woman, their professional identity can be eclipsed (see also Hatmaker 2012). In terms of the traditional FRS, the HM Fire Service Inspectorate (Home Office 1999, 23-4) noted that for women workers, therefore, “'fitting in' with the dominant culture... almost universally seen as the principal requirement for everybody in the service', could necessitate the impossible task of 'adopting a role that made their gender 'invisible'.

The role of uniform in the development and demonstration of body build capital and the problem of visibility should be raised here. The performance of body capital is, in part, a performance of 'aesthetic labour' (Nickson and Korczynski 2009), and firefighters' corporeality, including their general appearance and achievement of the right 'look' (Warhurst and Nickson 2001) (quasi-military, smart, capable, protecting and protected, sturdy), is part of the labour that the FRS expects from its workforce. Access to uniforms should accordingly augment women's ability to perform body build capital and thereby dim their gender difference and related visibility. However, evidence from the military suggests that sex-linked gender 
ultimately remains salient even in the uniformed body, and women's use of uniforms serves to confirm the androcentric norms of male-dominated organisations as much as it challenges them (Sasson-Levy 2003, 459).

\section{Modernisation - the move to a 'twenty-first century' organisation and the refocus on non-physical skills}

In 1999, the publication of Her Majesty's Fire Service Inspectorate's Thematic Review into Equality and Fairness in The Fire Service formed part of an extensive policy evaluation period that also included Lord Bain's Independent Review of the Fire Service (2002). The Equality review's 'overall conclusion' was that: 'the service is institutionally sexist', and needed to make 'rapid and fundamental changes' (Home Office 1999,68$)$ to its 'macho' (21) workplace culture.

Following this, the UK FRS became the focus of a modernisation and professionalisation programme designed to implement 'recommendations' for organisational change 'to meet the demands of the twenty-first century' (Bain 2002: i), and address those elements preventing it becoming a 'well balanced, modern working environment in which equality and fairness can flourish' (Home Office 1999, 22). A raft of policies, targets and initiatives followed (see, for example, CLG 2008). Particular elements of the historical culture were identified for change to improve the position of its existing workers, and to diversify the future workforce. These included the 'outdated, authoritative' management style (Home Office 1999, 22). The dominant occupational profile was similarly identified as in need of change, with uniforms characterised as reinforcing 'hierarchical differences or elitism', and delaying the emergence of an occupational image fit for 'the twenty-first century' (Home Office 1999, 22). 
Official statements on the skill-set required for FRS work subsequently delineated a considerably broader profile. Firefighting itself remains a role requiring no formal educational qualifications, although entrants have to pass a battery of written aptitude and practical tests, arguably the most stringent of which are physical, designed to screen for the ability to perform rigorous manual tasks associated with critical incidents (FRS 2012a). However, where physical build and prowess were once the overwhelming focus of recruitment, the post-review period has seen a concerted attempt to develop a more rounded and explicitly codified job description for firefighters. There has been a move away from entrance requirements that made it more likely that applicants would fit a standard physical type, for example height restrictions and upper age limits, and a greater emphasis on non-physical skills. The “'new look' firefighter is not...an individual...focused on the traditionally perceived role of attending Emergency Incidents and the physical requirements to achieve that' (FRS 2012b). Applicants are now carefully screened for administrative and organisational skills, and the following personal qualities and attributes (PQAs): confidence, resilience, openness to change, effective communication, problem solving, political/organisational awareness, planning and implementing, situational awareness, commitment to development, working with others, as well as a commitment to diversity and integrity (FRS 2004). Moreover, effort has been made to better recognise the role non-physical skills and qualifications play in the profiles of its crucial minority of non-operational workers.

The importance of a non-physical skill-set is further stressed as both operational and non-operational personnel move into leadership and management positions. Firefighters can only rise through the organisational structure by demonstrating the necessary PQA skills at the FRS's Assessment and Development 
Centres (ADCs) and promotion for non-operational staff depends significantly on the demonstration of these critical personal skills, and on the expectation that they will effectively manage a diverse portfolio of processes and personnel. Emphasis has been placed on the importance of producing greater clarity in relation to the technical elements of roles, tasks and skills and their assessment, in order to improve the likelihood of marginal workers reaching established targets regardless of their gender, ethnicity and other background characteristics.

As in other male-dominated occupations (Woodfield 2000), this modernisation process has led to greater expressions of optimism about the opportunities the Service can offer to women. In tandem with FRS-led initiatives, the organisation Networking Women in the Fire Service has played a key role in furthering progress on equalities and diversity. The FBU's role here has been more ambivalently characterised, however. On the one hand, it has been identified as pursuing equalities agendas (CLG $2010 \mathrm{~b}, 27)$ and as unmasking the review and modernisation process per se as an attempt to use 'women as an excuse to attack conditions of service' (NWCFBU 2003). Equally, however, the small amount of research focusing on the FRS in its post-review period has suggested that FBU resistance to modernisation still cannot be understood separately from its opposition to increased opportunities for women workers because both 'challenge the same phenomenon - the way firefighters see their job and construct their masculinity' (Baigent 2008). Ness's (2012) research on construction workers has argued that this complex dualism lies at the heart of working-class and male-dominated workforce resistance to the changes associated with modernisation because the 'encroachment of women on 'men's jobs' is seen as part of the encroachment of modernity' (663). Unsurprisingly, therefore, ThurnellRead and Parker (2008) have suggested that the traditional firefighter figure remains 
the dominant occupational profile for some FRS men, and that the primary occupational identification remains with 'manual masculinity' rather than 'mental manliness' (Thurnell-Read and Parker 2008, 133). Moreover, Hall, Hockey and Robinson (2007) have claimed that the increased codification and recognition of nonphysical traits is resisted as it signals a potential 'erosion of the brigade's discipline, professionalism and skill', but also disrupts 'the complex hierarchies of male sociality', and shifts 'understandings of work that is appropriate for men and women and their natural capabilities' (541).

The reified association between women and non-physical skills evident in both official optimism about the likelihood of workforce diversification within the new look service, and in the resistance to modernisation noted in some workers, assumes that such skills when possessed by women, will be recognised. Research elsewhere, however, suggests that this is not always the case. Indeed, there is evidence that the socio-political perception of skill becomes stronger when the skill in question is non-physical or 'intangible' as there is less clarity about what comprises such skills in the first place (Grugulis and Vincent 2009; Woodfield 2000), and what constitutes a technically competent demonstration of them. Jamous and Peloille's classic study (1970) of the reproduction of professionalism demonstrates that the process of social over technical selection intensifies where there is more indeterminacy in occupational profiles. The discursive space created by ill-defined areas of work roles leads to equally ill-defined arguments designed to include some individuals and marginalise others. Grugulis and Vincent $(2009,599)$ suggest that the emphasis particularly on 'soft skills' in organisations is problematic and often disadvantages workers as it 'may support and legitimize discrimination', because seemingly disembodied skills are assessed according to the gendered embodiment of 
the person displaying them. They also suggest, however, that 'such precarious skillfulness is not so apparent further up the hierarchy where soft skills seem to provide an additional dimension to work' (2009, 611). Ross-Smith and Huppatz $(2010,562)$ have further suggested that, in some arenas, women managers may be advantaged by their gender and gendered readings of their embodied labour. Taking up the Bourdieuian concept of gender capital, 'a form of limited 'embodied' cultural capital' (550), they acknowledge that 'white men' usually possess the gender capital (561) appropriate to the management field, and that women 'continue to be subordinately positioned' (563), but that 'female and feminine dispositions' have also 'become currency in the masculinized field of management' (563).

Research focusing on the extent to which women's management skills are recognised within male-dominated occupational contexts suggests that gender remains a determining factor, however (Cames, Vinnicombe and Singh 2001; Schein et al. 1998; Watts 2009). Management skills including intuition, flair, resilience, commitment, authority, experience, leadership, strategic thinking, interpersonal and communication skill, as with intangible skills more generally, are less easily and often overtly codified and demonstrable. Consequently, some research suggests that the recognition of such attributes remains contingent upon the taste and judgment of others, and that they are more readily assessed against the template of the dominant group. As is the case with physical skills, it has been claimed that this tendency is again intensified in organisations where men predominate, as the default mental 'type' that management candidates are measured against is more strongly masculine (Cames, Vinnicombe and Singh 2001; Schein et al. 1998; Woodfield 2000).

The research of Kanter (1977), and more recently Watts (2009), in highlighting the paradox of workplace visibility for women seeking recognition and 
progress into senior positions in male-dominated organisations, is relevant here. The goal of overcoming 'otherness' (Watts 2009, 515) and achieving 'invisible (wholly assimilated) bodily status' (517) forms a key criterion for advancement, and yet 'advancement and opportunity may accrue from being noticed or marked out' (526). For this reason, women's experiences of leadership and management roles necessitate ‘a degree of corporeal maneuvering not required of men’ (Binns, 2010: 165).

\section{Data and Methods}

A participant observation was undertaken on a two-day senior women's residential event at the FRS Headquarters, held approximately a decade after the review period. Twelve firefighter and 11 non-operational participants were managernominated for the event. All but one were white. Their ages ranged from mid-20s to mid-50s. All held managerial responsibilities and were identified as occupying leadership roles. Additionally, some held post-graduate qualifications, completed within the FRS's personal development framework, and so were among the more highly qualified personnel. Their relative success, and comparatively small number, means the research sample was restricted; this should be considered when reviewing the findings. Countering this proviso is the fact that participants were drawn from across the UK and a wide variety of FRS roles.

The event's format comprised plenary presentations and discussions as well as breakout sessions recorded on flip charts and was facilitated by an external consultant who stated its main aim as the creation of a context in which senior women could share their experiences and understanding of being a woman, and a woman leader, in the FRS. During the introductions, participants were strongly encouraged by the 
consultant to maintain 'a positive perspective'; it is worth noting in this regard that the majority repeatedly affirmed their commitment to the FRS and viewed it overall as a positive employment experience.

Participants were informed that I was in attendance as an invited researcher; observing, recording and taking notes. I wore a 'Researcher' name badge, and was identifiable as an outsider as participants knew each other from previous contact. Participants were invited to request further information about the research and advised that I would circulate a summary findings report for comment. I did not contribute to their plenary or breakout discussions, but otherwise engaged in informal conversation.

The data collected included my observation and conversation notes, and participants' flip chart notes, producing 80 pages of transcribed material. Additionally, the dataset included 11 'reflective comment' contributions, comprising 54 pages of typed or handwritten text; five from firefighters and six from nonoperational staff. Participants were invited to produce this material, for themselves or for consideration by FRS senior management and/or as research data. Following analysis, a 60-page summary report was circulated for comment. Ten participants responded, confirming that the report reflected their contributions and experiences. The research was completed in 2011.

The data was inductively coded and analysed by hand, the focus being the identification of recurring themes shaping participants' contributions.

Related points about intersectionality and anonymity should be highlighted here. Wright's (2008) evidence suggests that different types of FRS women have negotiated the problem of embodied skill and gender visibility in diverse ways. Her study of firefighters illustrates that lesbians displayed characteristics 'defined as 'masculine" (103), and so emphasized 'similarities with the dominant group' (2008, 
111), and distanced themselves from the positioning of heterosexual women as 'fire tarts' (107); in so doing they challenged traditional constructions of both masculinity and femininity in the organisation, and were consequently able to secure acceptance and skilled status more easily than heterosexual women. Wright identifies her participants' quotations only as lesbian or heterosexual, withholding further background information, 'given the very small numbers of women employed in the fire service' (2008: 105). For the same reason, participants' quotations are here identified only as 'firefighter' (F) or 'non-operational' (N-O) personnel, as this proved to be an important distinction.

\section{Findings}

\section{Negotiating physical skill recognition}

A decade on from the review period, the FRS was confirmed in the data as an occupation where working-class, masculine-typed body capital (Monaghan 2002) remained prominent and formed an important basis of all workers' occupational identity, feelings of integration and skill status. Male firefighters, and their body capital and skills, were characterised as 'the norm' (N-O1), and women's bodies confirmed as 'untypical' (F9). In this context, participants' commentary reflected the paradox highlighted elsewhere (Kanter 1977; Lewis and Simpson 2010; Watts 2009) whereby the central occupational type becomes invisible by virtue of its dominance and atypical workers become more visible because they diverge from it.

Most participants reported strong responses to being 'other' to the prototypical worker on joining the Service, with more extreme responses coming from non-operational women: 'felt like [I was] in goldfish bowl for weeks' (N-O4); 'felt physically sick' (N-O5). Participants further identified the existence of a female 
prototype, counterposed to the male firefighter prototype, against which they were 'struggling, mostly in silence' (F4). This prototype was a parodic, 'cartoon' representation of an overtly 'sexual', 'frivolous', 'dependent' woman. It was rarely in evidence in pornographic posters in stations, as it had been in the past, and participants acknowledged the positive steps taken in the post-review period to eradicate this and some other 'worst elements' of FRS culture. The prototype remained, however, within the 'assumptions', and 'inappropriate' images and 'banter' of informal FRS culture, and was perceived in formal decisions, such as the Service's choice of a celebrity role model to front an awards ceremony: 'only for the men in the audience ... she had a see-through dress on' (F3).

In this context, the female body and gender visibility signalled difference, risk and vulnerability, and underscored the precariousness of women's presence and integration within the Service. Specifically in terms of physical skills, participants were conversant with FRS policies designed to encourage diversity among operational roles, where the formal requirement for physical skills lay, and reported benefits from such policies, for instance women-only physical try-outs for applicants. They 'heard' equalities discourses during everyday interactions, in both informal and formal settings. They nevertheless reported that a default, common-sense, counterdiversity discourse was frequently more dominant, and that this continued to position men's bodies as ideal, and women's as less able to achieve the required levels of strength and prowess for operational roles.

Commentary suggested that the relationship between men and physical skill was perceived to be seamless, innate and relatively unchallengeable; any physical activity constituted an enactment, and often confirmation, of male firefighters' body capital. Echoing Monaghan's distinction between 'superordinate' and 'subordinate' 
masculinities $(2002,340)$, participants' discussion of male firefighters focused on the 'supremely fit' and the 'unfit', and was often humorously-framed. Accordingly, the very fit were sometimes described as obsessed with, for example, 'weights', 'sport and fitness'. Participants revelled in any physical lapses amongst this group:

A group of women ( $\mathrm{F}$ and $\mathrm{N}-\mathrm{O}$ ) introduce, and repeatedly return to, the topic of two 'very fit', uniformed men (one very senior) experiencing slapstick falls. Lots of humour, but more muted from firefighters. All hold obvious respect for individuals involved and their physical capacities. (Observation note)

Humour was equally evident in discussion of 'unfit' male firefighters, with one described as 'like Homer Simpson' (N-O10). Notwithstanding this tone, participants were clear that all male firefighters benefitted from the 'petty dividends' (Baigent 2001, 97) conferred on them by the ideal type of firefighters' embodied masculinity, so that sometimes sub-optimal male embodiment itself was sufficient basis for capitalizing on firefighter body capital:

He's a big macho man but no one's questioned how big he is ... he's huffed and puffed around the place for years. If that was a woman, something would have been said ... How can he do his job? (N-O10)

The framing of these discussions simultaneously revealed participants' collective recognition of, and challenge to, the idealized form of firefighters' masculinity, as validated through masculine body capital. It is interesting to note in relation to this that non-operational men were not mentioned at all in the data. 
Despite no overt requirement to measure up to the masculine firefighter body capital standards, non-operational women nonetheless felt themselves to be assessed against this ideal template. They also, therefore, reported open scrutiny of their physicality. One non-operational participant, for example, described having her performance at a charity sports event picked over and criticised by male firefighter colleagues. Non-operational participants also felt the effects of their distance from the body capital ideal type in the assessment of their skills in the Service:

I don't think they can see past all this [gesturing to body] to see what I can offer (N-O3).

Moreover, these participants felt they were culturally allocated to a space closer to the prototype of femininity counterposed to this male ideal; one participant described how she struggled to position herself between the 'options' of 'being propositioned...[or]... ignored, discounted' (N-O2).

Firefighter participants also noted the minimal discursive space to 'just be a normal woman' (F2) in the organisation. They differed from non-operational women, however, in more explicitly describing a process of self-othering in the face of the default feminine prototype, but also in terms of their efforts to forge an alignment with male firefighters, and their body capital currency. These women had undertaken concerted projects to 'blend' and 'fully integrate' into watches when first joining the Service, and erased overt signifiers of femininity as part of this process:

No jewelry, make-up, on watch obviously, but then I stopped wearing it outside too. (F12) 
Non-operational participants noted the sometimes-extreme impact this greater need to blend in had on firefighter colleagues:

Some girls take the pill all the time to not have ... [menstrual periods], like in the army. You shouldn't have to medicate yourself to work, but they do. (NO1)

Firefighter participants' alignment to firefighting men and the masculine body capital template did not ensure an objective assessment of their skills, however. Although all had passed the strenuous physical entrance tests, and continued to engage in high levels of physical activity, they described pressure to demonstrate their fitness, and a greater surveillance of their physical capacities than was the case with men:

We are measured against the perfect male specimen. (F10)

You have to do better, make no mistakes. (F4)

Acknowledging that they 'could normally not match men pound for pound' (F5), firefighter participants emphasised their willingness to put themselves at physical risk, but also their intense self-vigilance around fitness levels. As with Monaghan's female doorstaff, the focus fell on the 'technique' aspect of body capital (2002, 337), to demonstrate occupational competency. Excellent performance in 
terms of technical tasks could still leave women firefighters facing challenge, however:

It is all about technique, so quite small people can carry ladders and lift big people... how come then women are 'a risk'? (F1)

The attempted alignment with the FRS's masculine body capital model had significant impacts on women firefighters, leading, for instance, to a reluctance to be identified as a woman in the work context:

I am not a "woman" firefighter, I am just a firefighter. (F7)

This alignment forestalled acknowledgement that women might have specific physical needs in the workplace. Participants balked at 'requesting support because of physical difference' (F10), often withstanding discomfort in order to avoid drawing attention to it; managing without complaint mixed-sex sleeping quarters and bathrooms, ill-fitting uniforms or personal protective equipment, and arguably thus risking optimal performance. Some firefighter participants also discussed strong feelings about being positively identified with other women, and resented being singled out to represent 'women's issues' (F12):

All my efforts to blend in wiped away in a second. (F1)

I've resisted, resisted, resisted being involved in things that single us out as different. (F10) 
The commentary of non-operational women indicated a clear awareness of firefighters' primary alignment, and recognised that firefighters alone benefitted from the 'petty dividends' (Baigent 2011,21) their closer proximity to the masculine ideal type conferred: "they are still seen as "core business" and what they do is seen as more important' (N-O1).

\section{Negotiating the recognition of non-physical skills}

As was the case with physical skills, the commentary relating to non-physical skills indicated overall that the association of men and management skill seemed natural and deep-seated. Possessing the requisite body capital was closely linked to the Service's management culture and style: 'big, loud, men in big, loud uniforms' (N-O2), and to the assessment of managerial and leadership skill:

The culture is very male-oriented...when you go to meetings attended by uniformed staff you have to compete for attention with people who talk across each other...competing with each other for the attention of senior officers. $(\mathrm{N}-$ O3, Reflective Comment)

Again, senior men who participants identified as 'unfit' to manage, were described as still achieving skilled status in this regard by their close alignment to the firefighter ideal type: 
He is a bully and can't understand that...you can't manage people through fear effectively for very long. He fits the mould though, of a "big uniform", doesn't he? (N-O8)

In this context participants reported that achieving skilled status for their nonphysical, management and leadership skills was just as complex and difficult as achieving skilled status for physical capabilities. Furthermore, the process was represented as one in which visibility dilemmas were re-presented, and often intensified. A pre-requisite for being selected for seniority was the identification of above-average non-physical skills in a candidate, which, by definition, involved heightened visibility (Kanter 1977; Watts 2009) and, as has already been discussed, many women equated visibility with gender salience, and intensified recognition of their non-conformity with the ideal type of worker:

I'm more conspicuous now. (F2)

I stick out like a sore thumb. (N-O2)

This conspicuousness in turn was recognised as increasing their vulnerability to being deemed substandard and unskilled, rather than being recognised for the above-average skills that formed the basis of their promotion. All participants, again, felt themselves subject to more scrutiny and judgment than was the case with comparable men: 
Compare $[\mathrm{me}]$ against my male counterpart who I have real experience of having very little output, and this is left unchecked - an accepted way of working for this particular employee. (N-O2)

Some non-operational participants described experiencing organisational 'culture shock' on entering the Service from management posts elsewhere:

I was so shocked...I have a lot of experience and qualifications...they count for nothing. (N-O3)

I was very established in my profession and held a senior post... when I came here...no one really listened to anything I said, or thought that I knew anything - at first I wondered why they had employed me...a female manager in the Fire Service is the toughest job I have ever experienced. Every day... I feel as though I have to prove myself as competent and capable. (N-O2)

Non-operational participants felt pressure to conform to the prevailing management approach to be recognised as skilled: 'I am only really effective in meetings when I act like they do' (N-O10).

Again, there were suggestions that optimal performance was jeopardised because participants felt 'If I need something to happen - I have to prepare for a battle to obtain it' (N-O11). Those who had worked elsewhere, however, felt they brought with them 'a language' to 'tackle things' (N-O4).

Firefighter participants also perceived the pressure to 'fit in with the traditional way of managing' (F12), to 'conform to male traits to get 
on...make...gender invisible' (F5), but most had no experience of alternative organisations, and certainly not of managing elsewhere. By contrast with nonoperational women, however, they could more easily align themselves with the dominant ideal type of manager, based on their closer proximity to the operational ideal. Nevertheless, most firefighter participants experienced this alignment capacity as simultaneously threatening the close relationships they had previously forged with firefighting men and 'manual masculinity' (Thurnell-Read and Parker 2008, 133), and experienced their advancement partially as a transition towards a more white-collar occupational identity. Consequently, although some commentary referred to receiving support from non-managerial firefighter colleagues 'as I've come through the ranks' (F3), 'haven't been parachuted in [by contrast with some non-operational managers]' (F1), other contributions suggested former colleagues were 'watching and waiting for you to fail' (F4). Firefighter and non-operational women differed in respect of this aspect of their experience of seniority precisely because the latter had less developed bonds with the core firefighter role and were more ambiguously positioned in relation to its ideal type status.

Neither firefighter nor non-operational participants suggested they felt the Service's management style was one they would freely choose. They aspired to a more 'authentic' style that was 'non-hierarchical', 'transformative', 'trust-based', while acknowledging the limited cultural space to develop this. Anxieties about personal visibility were abundant in this commentary, especially from firefighters, as participants articulated the dilemma they faced choosing between conformity and confrontation because 'challenge is a form of making [the] self visible' (F6).

Participants clearly identified that difficulties lay in the fact that their nonphysical skills were less determinate (Grugulis and Vincent 2009; Jamous and Peloille 
1970) than physical skills. One very senior participant described her history as someone who could easily undertake 'all the individual, technical tasks' associated with seniority, while line managers continuously commented that she 'lacked gravitas' (N-O5). Participants focused on clearer performance and promotion assessment criteria as the most useful change the FRS could make that could support better recognition of non-physical skills. Clarity was understood to mitigate sociopolitical judgments: 'If the performance goals are clear, it matters a lot less what people think of you personally' (N-O1).

Some felt that the 'new look' FRS emphasis on identifying leadership potential by measuring 'soft skills', and focusing on PQAs, worked well, and that, in line with the official professionalisation rationale that underpinned it, this refocusing would successfully diversify management. More commonly, however, firefighter and non-operational participants came together in identifying this aspect of the modernisation process as 'a barrier to promotion' (F10). The central problem identified was precisely the focus on non-technical, difficult-to-measure, aspects of skills and roles:

Before...we did an exam about technical competence; now ...[it] is about ... sitting in group discussion, that's about talking to people. (F9)

If you have to have this... what's wrong with pairing it with old-fashioned exams? (F4)

Furthermore, participants feared that the new processes, in moving away from technical elements of skills, would merely confirm the androcentric leadership type: 
They say 'we want soft skills' but I had no preparation or training...Does it mean 'be nice'? Clearly not. Some of the men were not being soft at all...it could have been designed ...to destroy my confidence. (N-O7)

Indeed, there were suggestions that the 'old-style' FRS personnel and procedures had produced better contexts in which marginal workers' skills could be judged:

People with awful reputations can be great...old-fashioned leaders. Don't bother with female status but...clear setting of standards and performance. (NO2, Reflective Comment)

Before it was clearer that you were progressing because you had met the right standards. There is more of the fluke element now. (N-O3)

\section{The role of uniform}

The role of FRS uniforms, ranks and rank markings was notable in participants' commentary. For some, and here non-operational women were over-represented, these quasi-militaristic features were divisive, cleaving rank from rank, operational from non-operational staff, including operational women from non-operational women. Uniforms were acknowledged to signal organisational centrality and status, but also to dim the gender salience of operational women, and disrupt gender-based alliances: 'it's harder to see the things we share and to identify with each other when we are divided into...two completely different categories' (N-O1). 
Consequently, some argued for the complete removal of ranks and uniforms, save for when they were critical to operations, or the adoption of a common service uniform and command chain across all roles, whether operational or non-operational. This could move the FRS from a 'military culture to a more corporate' (N-O10) one, and towards an organisational context within which equality and diversity initiatives could embed. Structural hierarchies between workers would 'not be immediately visible' (N-O11), and status and respect would be 'earned' (N-O3).

Firefighters tended not to agree, countering that:

Uniforms make no difference...rank markings don't make people bullies bullies make people bullies. (F3)

Frustrated with some of the women in non-ops roles... a lack of understanding ... of the issues faced by female/minority FFs (F1, Reflective Comment)

Here, the majority saw uniforms as a key tool in their past and ongoing alignment strategy, and so in the drive to be recognised as skilled. They perceived extra pressures to conform to the occupational ideal type, and, in this context, their gendered bodies, while not eclipsed by uniform, were muted; as were the sociopolitical judgments of skill that they triggered. Uniforms helped achieve uniformity, reduced the perception of difference that would be "more obvious if clothing was civilian' (F12), and supported attempts to achieve the right body build (Monaghan 2001) and aesthetic look (Nickson and Korczynski 2009). Despite some uniforms being unsuited to women's bodies, and challenging optimal physical performance, they allowed physical and non-physical skill to be viewed against a 'more neutral' 
(F5) canvas. Firefighters positively described being 'mistaken for men' at incidents: 'people can't see what you are under all the gear' (F4), and feeling more 'relaxed' in uniform, with 'less to prove' (F3). In terms of promotion, uniforms and ranks were similarly seen as aiding skill recognition:

It's sometimes easier to be taken seriously in uniform...I have earned these...[rank markings] and these tell everyone that. These are going to stop someone in their tracks who might question me. (F12)

Management and leadership skill was therefore made more determinate by uniform wearing; it supported operational women's embodied display of competence, dissipating challenges based on socio-political rather than technical judgments. For non-operational participants who had experienced wearing a uniform, this benefit was also recognised: 'It is an objective status symbol that everyone recognises' (N-O5).

\section{Conclusion}

The findings here confirm and extend understanding of the link between skilled status and gender in the workplace, and especially the experiences of women in occupations where men, and particular constructions of working-class masculine embodied competence, dominate. Participants' accounts emphasised that skill assessments are always embodied processes (Philips and Taylor 1980; Watts 2009). Their bodies signified a subordinate gender status, and with this signification, labour and competencies were perceived as less valuable. Also emphasised was the 
powerful, centrifugal pull to the norm that women experience in organisational cultures marked by a strong, male, worker identity.

The research supports findings elsewhere giving pause to optimistic readings of modernisation processes in organisations, and the workforce diversification they are often ostensibly aimed at achieving (Watts 2009; Woodfield 2000). Commentary here suggests that slow progress has been made in relation to injunctions to move away from an old-style firefighter profile and culture, to 'new look' working context (Home Office 1999). Despite modernisation initiatives, participants indicated that the traditionally idealized firefighters' masculine body capital (Monaghan 2002) remained central to the dominant FRS occupational identity and defined skilled status; it operated as a yardstick against which women's physical skills, however technically accomplished, would always be judged as subordinate to even those possessed by subordinately masculine men (Monaghan 2002, 340). Non-operational women perceived themselves to be assessed according to the same yardstick despite no overt requirement for them to be physically capable. Non-operational men were not explicitly mentioned, but all operational men were perceived to benefit from the conferment of dividends (Baigent 2001, 21) following their alignment to the organisation's ideal type.

Participants additionally described experiencing difficulties in having their non-physical, management and leadership skills, recognised. Rather than being advantaged by their seniority (Grugulis and Vincent 2009, 611), or their possession of 'gender capital' in management roles (Ross-Smith and Huppatz 2010), they perceived the dominant organizing and leading styles as also calibrated against firefighters' masculinity and oriented towards high visibility body capital performances. Although class itself was not explicitly mentioned, its presence was felt in commentary as 
participants indicated that the salience of this occupational ideal partially inverted the usual hierarchies of non-manual/white-collar versus manual/blue-collar work and skills (see also Baigent 2001; Woods 2002). For firefighter women, the transition to a senior role could be experienced as unsettling both the class and gender alignments they had forged with male firefighters. More broadly, both firefighter and nonoperational participants indicated that non-physical skills, especially when their assessment criteria remained indeterminate, were at least as vulnerable to being measured according to socio-political judgments (Grugulis and Vincent 2009; Jamous and Peloille 1970; Woodfield 2000) as physical skills, and that this vulnerability contributed to a workplace context within which neither skill-set was deployed to full effect.

Participants recognised that without post-review equality policies, their working experiences would be harder still, and that these initiatives were a necessary, if not a sufficient condition for progress around equality issues in the FRS. Notwithstanding this acknowledgement, it is clear that discourses and policies developed at the level of formal organisational culture and which are claimed to modernise, professionalise and diversify it, can have unintended consequences and ultimately disadvantage minorities if the informal culture evolves more slowly.

Binns' observation that women's leadership experiences necessitate 'a degree of corporeal maneuvering not required of men' (2010: 165) was confirmed here. Participants' repeatedly expressed anxieties about personal, embodied visibility and the effect of heightened visibility accompanying promotion, which was perceived to intensify gender salience and socio-political judgments about skilled status (Kanter 1977; Watts 2009). The common decision to seek gender dimming and/or alignment with the prototypical worker did not indicate that participants unreflectively aspired to 
masculine, or 'macho' displays of the requisite body capital, or leadership style, but that they recognised that attempting to achieve skilled status outside of these accepted parameters would prove more difficult. The ultimate concern of all participants here was to avoid the undesirable fate of achieving heightened visibility as a woman, but lowered visibility as a skilled worker (Hatmaker 2012).

Non-operational and firefighter women had access to different tools and strategies to deal with their working context, and it was clear that the latter were more able to align themselves with men and masculine body build capital and so engage differently with the boundaries between 'masculinity' and 'femininity' (Wright 2008). Some commentary indicated that the asymmetrical paths available to firefighters and non-operational women created in-group fissures symptomatic of the ingrained 'us and them mentality' identified as problematic in the traditional FRS (Home Office 1999, 21). Firefighters could benefit from their closer alignment with elements of the traditional culture - from their physical alignment with the ideal type of worker and their historical integration into watch culture, avenues not open to most nonoperational participants. Management and leadership roles themselves remained marginal to 'core business' of the firefighter ideal, but senior men, and to a lesser extent, senior women firefighters were perceived to continue in their alignment with firefighters' masculine body capital when promoted, and so benefit from its 'dividends' (Baigent 2001, 21). Firefighters could also benefit from the uniform and from the fact that it continued to reinforce the 'hierarchical differences' and traditional androcentric culture identified and lamented during the review period (Home Office 1999, 22; see also Sasson-Levy 2003, 459); this was especially important given the sometimes indeterminate nature of managerial skill assessments. Conversely, non-operational participants did not to the same extent face the difficult 
possibility of breaching previously close watch relationships on being promoted, or when developing a critical stance towards traditional FRS culture.

The potentially substantial benefits that firefighter and non-operational women would secure from forging closer, gender-based alliances are currently thwarted by the dominant occupational profile of the Service and their asymmetrical access to its dividends and to strategies to challenge it. The evidence presented here consequently underscores the established wisdom of networking schemes for women in such contexts. The close of the event saw the majority of operational and nonoperational women building on identified common ground and agreeing that forging stronger gender-based rather than role-based alliances was one of the most positive steps that could be taken to improve their working lives:

'coming here makes it seem normal to be a woman leader' (N-O10)

'this is the first time ... I've felt comfortable and secure enough to identify myself with other women' (F9)

\section{Acknowledgements}

I would like to thank the Fire and Rescue Service personnel whose accounts this research is based upon and the anonymous referees for their helpful comments. 


\section{Bibliography}

Baigent D (2001) One more last working class hero: A cultural audit of the UK fire service. Unpublished doctoral thesis, Anglia Polytechnic University.

Baigent D (2008) Early Summary for “One Decade On” (4408) http://fitting-in.com.

(Date of Retrieval: $31^{\text {st }}$ July 2013).

Bain G (2002) The Future of the Fire Service: Reducing risk, saving lives. Independent Review of the Fire Service, December.

Binns J (2010) Leadership and the (In)visibility of Gender. In: Lewis P, Simpson R (eds) Revealing and Concealing Gender: Issues of Visibility in Organizations. London: Palgrave Macmillan.

Bourdieu P (1986) The Forms of Capital in Richardson, JG (ed), Handbook for Theory and Research for the Sociology of Education. New York: Greenwood, 241258

Cames I, Vinnicombe S, and Singh V (2001) Profiles of "successful managers" held by male and female banking managers across Europe. Women in Management Review 16(3): 108-117.

CLG (Communities and Local Government). (2010a). Fire and Rescue Service: Operational Statistics Bulletin, Crown copyright.

CLG (2010b). Fire and Rescue Service Equality and Diversity Report, March, Crown copyright.

CLG (2008) Fire and Rescue Service: Equality and Diversity Strategy 2008 - 2018, May, Crown copyright. 
National Women's Committee Fire Brigades Union (NWCFBU) (2003) Women's

T.U.C., Emergency FBU motion: http://www.nwcfbu.co.uk/tuc/tuc 03.php. Date of retrieval: $20^{\text {th }}$ September 2014)

FRS (2004) Fire and Rescue Service Overview Personal Qualities and Attributes (PQAs) Framework - Operational Roles.

http://www.frsdevelopment.com/docs/pqaframework.pdf Crown Copyright (Date of Retrieval: 10th September 2012)

FRS (2012a) The Personal Qualities and Attributes. Fire and Rescue Service. http://www.fireservice.co.uk/recruitment/pqas (Date of Retrieval: 10th January 2012) FRS (2012b) National Firefighter Selection Guidance Notes. http://www.hantsfire.gov.uk/southeastguidance.pdf. (Date of retrieval: 10th September 2012)

Grugulis I, Vincent S (2009) Whose skill is it anyway? 'soft' skills and polarization. Work, Employment and Society 23(4): 597-615.

Hall A, Hockey J, and Robinson V (2007) Occupational Cultures and the Embodiment of Masculinity: Hairdressing, Estate Agency and Firefighting. Gender, Work and Organization 14(6): 534-551.

Hatmaker DM (2009) Engineering Identity: Gender and Professional Identity Negotiation among Women Engineers. Gender, Work and Organization 20(4): 382396.

Henwood, F (1998) Engineering Difference: Discourses on gender, sexuality and work in a college of technology. Gender and Education 10(1): 35-49. Home Office (1999) Equality \& Fairness in the Fire Service: A Thematic Review by HM Fire Service Inspectorate, September. 
Jamous H, Peloille B (1970) Changes in the French University Hospital System In: Jackson JA (ed): Professions and Professionalisation. Cambridge: Cambridge University Press.

Kanter R (1977) Men and Women of the Corporation. New York: Basic Books.

Lewis P, Simpson R (2010) (eds) (In)visibility of Gender' In: Revealing and Concealing Gender: Issues of Visibility in Organizations. London: Palgrave Macmillan.

Mead M (1949) Male and Female. New York: William Morrow \& Co.

Monaghan LF (2002) Hard men, shop boys and others: embodying competence in a masculinist occupation. The Sociological Review 50(3): 335-355.

Ness K (2012) Constructing Masculinity in the Building Trades: 'Most Jobs in the Construction Industry Can be Done by Women'. Gender, Work and Organization 19(6): 654-676.

Nickson D, Korczynski M (2009) Editorial: Aesthetic Labour, Emotional Labour and Masculinity. Gender, Organization and Society 16(3): 291-299.

Ortner, SB, Whitehead H (1981) Sexual Meanings: The Cultural Construction of Gender and Sexuality. Cambridge: Cambridge University Press.

Phillips A, Taylor B (1980) Sex and Skill: Notes towards a Feminist Economics. Feminist Review 6(7): 79-83.

Ross-Smith A, Huppatz K (2010) Management, Women and Gender Capital. Gender, Work and Organization 17(5): 547-566.

Sasson-Levy O (2003) Feminism and Military Gender Practices: Israeli Women Soldiers in "Masculine” Roles. Sociological Inquiry 73(3): 440-65.

Schein VE, Mueller R, Lituchy T and Liu JL (1998) Think manager - Think Male: a global phenomenon? Journal of Organisational Behaviour 17(1): 33-41. 
Thurnell-Read T, Parker A (2008) Men, masculinities and firefighting: Occupational identity, shop-floor culture and organisational change. Emotion, Space and Society 1(2): 127-134.

Traweek T (1989) Beamtimes and Lifetimes: The world of high-energy physicists. Cambridge, Mass.: Harvard University Press.

Wacquant L (1995) Pugs at Work: Bodily Capital and Bodily Labour Among Professional Boxers. Body \& Society 1 (1): 65-93.

Warhurst C, Nickson D (2001) Looking Good, Sounding Right. London: Industrial Society.

Watts JH (2009) Leaders of men: women 'managing' in construction. Work Employment and Society 23(3): 512-53.

Woodfield, R. (2000) Women, Work and Computing. Cambridge: Cambridge University Press.

Woodfield, R. (2007) What Women Want from Work: Gender and Occupational Choice in the $21^{\text {st }}$ Century. London: Palgrave MacMillan.

Wright, T. (2008) Lesbian firefighters: shifting the boundaries between "masculinity" and "femininity". Journal of Lesbian Studies 12(1): 103-114.

Biography: Ruth Woodfield's research primarily focuses on gender differences and inequalities in the context of organisations, especially those in paid employment and educational spheres. 